\title{
Optimal Operation of Combined Heat and Power under Uncertainty and Risk Aversion
}

\author{
Lajos Maurovich-Horvat \\ Department of Statistical Science, University College London \\ Paula Rocha \\ Department of Statistical Science, University College London \\ Afzal S. Siddiqui* \\ Department of Statistical Science, University College London and Department of Computer \\ and Systems Sciences, Stockholm University
}

\begin{abstract}
Despite the proven benefits of combined heat and power (CHP) and recently introduced subsidies to support it, CHP adoption has not met its targets. One of the possible reasons for this is risk from uncertain electricity and gas prices. To gain insights into the risk management of a CHP unit, we develop a multi-stage stochastic mean-risk optimisation model for the medium-term management of a distributed generation system with a gas-fired microturbine with heat recovery and a boiler. The model adopts the perspective of a large consumer that procures gas (for on-site generation) and electricity (for consumption) on the spot and futures markets. The consumer's risk aversion is incorporated into the model through the conditional value-at-risk (CVaR) measure. We show that CHP not only decreases the consumer's expected cost and risk exposure by $10 \%$ each but also improves expected energy efficiency by 4 percentage points and decreases expected $\mathrm{CO}_{2}$ emissions by $16 \%$. The risk exposure can be further mitigated through the use of financial contracts.
\end{abstract}

Keywords: Combined heat and power, risk management, stochastic

\footnotetext{
*Corresponding author

Email address: afzal.siddiqui@ucl.ac.uk (Afzal S. Siddiqui)
} 
programming

\section{Introduction}

Mitigating climate change has become one of the main drivers behind energy policies, especially in the European Union (EU), where the long-term stabilisation of $\mathrm{CO}_{2}$ levels has become a priority. The EU aims to achieve $60-80 \%$ $\mathrm{CO}_{2}$ emissions reduction by 2050 relative to 1990 levels by increasing renewable energy production and by significantly improving the energy efficiency on both the demand and supply sides [1]. However, since the deregulation of the electric power industry, private investments have been modest [2]. Thus, in order to attract investment for sustainable energy, the EU has had to introduce generous subsidies. This, in turn, has led to more volatile electricity prices and has posed severe challenges to the transmission network due to the intermittency of renewables. To alleviate these effects, it will be necessary to retain conventional generation for the foreseeable future. Nevertheless, it is widely argued that the current central-station paradigm for electricity generation is unsustainable in the long term as a result of low energy conversion efficiency and transmission losses $[3,4,5,6]$.

A possible pathway for a sustainable energy transition is via the use of distributed generation (DG). As electricity is produced close to consumers, DG reduces transmission losses and allows for waste heat recovery. Thus, even though the electricity conversion rate for DG is lower than that of large power plants, the overall energy efficiency of DG system with a CHP is significantly higher $[7,8]$. For the aforementioned reasons, Germany has adopted three CHP laws to support investment into small- and large-scale CHP $[9,10,11]$. However, the targets regarding the higher share of cogeneration have not yet been achieved [12]. One of the possible reasons for lower than expected investment in CHP is uncertainties of electricity and gas prices in deregulated markets [13]. Financial risk is considered by [14] and [15] as one of the main barriers for investing in energy-efficient technologies. Likewise, [16] argue that middle-level managers 
show strong bias against risk as a result of flawed reward systems within companies.

In order to examine the risk that investors in CHP face, we formulate a multistage, mean-risk optimisation model for the medium-term management of a DG system with installed CHP. Our objective is to gain insights into managing risk using futures contracts and on-site generation. We assume uncertain electricity and gas spot prices and the availability of monthly and weekly electricity futures and monthly gas futures. We consider a large consumer that meets its electricity demand by either purchasing electricity from the markets or through on-site generation. In addition, the consumer satisfies its heat loads by using either a boiler or heat recovery. We find that the use of CHP not only lowers the consumer's expected running cost significantly but also reduces its risk exposure compared to on-site generation without heat recovery or to purchasing all electricity from the main grid. We also find that the availability of monthly gas futures increases on-site generation with CHP, thus indicating that CHP and gas futures are complements. A priori, the conditions under which physical and financial operational hedges function as substitutes or complements are neither evident nor explored in the extant literature. Hence, our modelling effort seeks to tackle this issue in order to provide managerial and policy insights that will be relevant for Germany and other industrialised nations grappling with a transition to more sustainable energy technologies.

The remainder of this paper is structured as follows. In Section 2, we provide a brief literature review of the related work. In Section 3, we introduce the decision-making framework and the problem formulation. Section 4 presents the numerical examples, and Section 5 summarises the main insights. Finally, conclusions are drawn in Section 6.

\section{Literature review}

Deterministic models for DG demonstrate that consumers with on-site generation can increase their energy efficiency significantly. [8] compare the economic 
benefit of installing different types of DG at a hypothetical microgrid via the Distributed Energy Resources Customer Adoption Model (DER-CAM). Using mixed-integer linear programming (MILP), they find that investing in gas-fired CHP turbines leads to the lowest energy cost and also reduces $\mathrm{CO}_{2}$ emissions. Focusing on the medium-term operational problem of an industrial consumer, [17] also use an MILP to determine the optimal scheduling for a CHP system. Meanwhile, [18] have a deterministic MILP for long-term strategic decision making in public buildings.

Studies with uncertain energy prices also exhibit the economic benefits of DG. Using real options valuations, [19] find that, under higher price volatility levels, it is more profitable to invest in a CHP system than in conventional generation. Similarly, [20] observe that high electricity price volatility relative to that of natural gas generation cost increases the value of a CHP investment.

While real options analysis provides insights into the investment decision, it does not address the operational risk of running a CHP under uncertain prices. One of the main mathematical tools used to model decision making under uncertainty is stochastic programming [21]. Stochastic programming is applied in [22] and [23] to examine the optimal operation of an electricity retailer and power producer, respectively. The electricity procurement problem of a large consumer with a self-production unit is considered in [24]. In a similar vein, [25] approach the problem of a large electricity consumer facing uncertainty in electricity prices with the possibility of meeting its (deterministic) demand using spot purchases, supply contracts, and self-generation with a deterministic cost over a six-month horizon by implementing a multi-stage stochastic programming framework. Introducing CHP in a stochastic programming model, [26] take the perspective of a risk-averse utility that must meet the stochastic electricity and heating demands of its customers via cogeneration, electricity spot purchases, and electricity futures purchases. [27] tackle the day-ahead CHP scheduling problem of a risk-averse consumer facing uncertainty in electricity prices and demand with a deterministic self-generation cost. In contrast to the numerous deterministic and real options papers on CHP investment, [28] apply stochastic 
programming to examine a consumer's prospects to invest in CHP.

Our research contributes to the existing literature as follows. Similar to [24], [25], [26], and [27], we examine the stochastic energy-sourcing problem faced by a large consumer, but we investigate how both the consumer's electricity and heat loads are met as well as the possibility of using CHP in addition to a microturbine without heat recovery. Furthermore, we assume that both electricity and gas spot prices are uncertain and futures prices are marked-to-market in every period, which is not the case in the literature that we have surveyed. Consequently, the interaction between physical, i.e., pertaining to equipment operation, and financial, i.e., dealing with forward contracts for both electricity and gas, hedges has not been adequately explored, thereby limiting managerial and policy insights. Analogous to [28], our paper provides insights into the interaction of financial hedges and on-site generation, but we focus on a consumer's risk management in the medium term instead of its long-term investment decisions. We also report on how different technologies can contribute to reaching the $2020 \mathrm{CO}_{2}$ emissions targets.

\section{Decision-making framework}

\subsection{Assumptions}

We address the operation of a DG system over a one-month time horizon that comprises four weeks. Each week is subdivided into $T$ time periods of equal duration. The DG system consists of a gas-fired microturbine with heat recovery, a boiler unit, and deterministic electricity and heat loads (Fig. 1). The consumer can purchase electricity from the spot market and from the weekly and monthly futures markets. The monthly electricity futures have either an offpeak load, a peak load, or a base load profile, while the weekly electricity futures contracts can be purchased for base load and peak load periods. Moreover, the consumer can generate electricity using gas from the spot and monthly futures markets while recovering waste heat. Similarly, the consumer can produce heat with the boiler unit using gas from the spot and monthly futures markets. 
To take into account possible risk preferences, we assume that the consumer's objective is to minimise its expected cost plus a risk measure with weight $B$. For the risk measure, we use the conditional value-at-risk (CVaR), which estimates the expected loss with a confidence level $A \in[0,1)$ in the worst $(1-A) \times 100 \%$ of cases (Fig. 2). CVaR is formulated with the help of the value-at-risk (VaR), which defines losses at the $(A \times 100)$-th percentile. As VaR is a threshold value (i.e., the probability that the loss exceeds this value is $1-A$ ), in contrast to CVaR, it does not provide any information regarding the size of loss beyond this level. In addition, CVaR is a coherent risk measure [29], and therefore, unlike VaR, it does not violate the sub-additivity property, i.e., the CVaR of a portfolio of different assets is always less than or equal to the sum of CVaRs of all assets considered individually. Finally, as CVaR can be formulated using linear programming, it is suitable for optimisation problems [30]. For these reasons, we prefer to use the CVaR rather than the VaR to examine different regimes for the consumer in terms of risk aversion, such as $B=0$ for risk neutral and $B>0$ for risk averse.

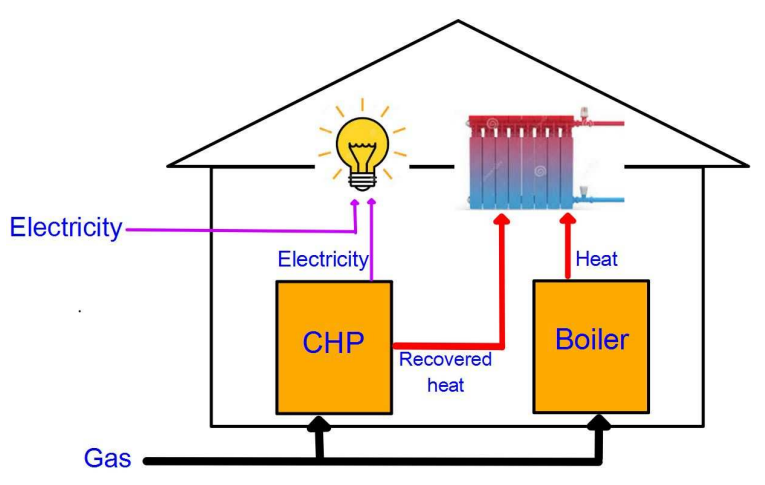

Figure 1: Stylised distributed generation system with CHP

To reduce computational complexity, we approximate the true distribution of the random electricity and gas prices by an approximation in the form of a five-stage scenario tree (Fig. 3) in which each non-root node corresponds to a state of the world spanning one week. Each node of the tree represents a point at which decisions are taken based on the realisation of the random parameters 


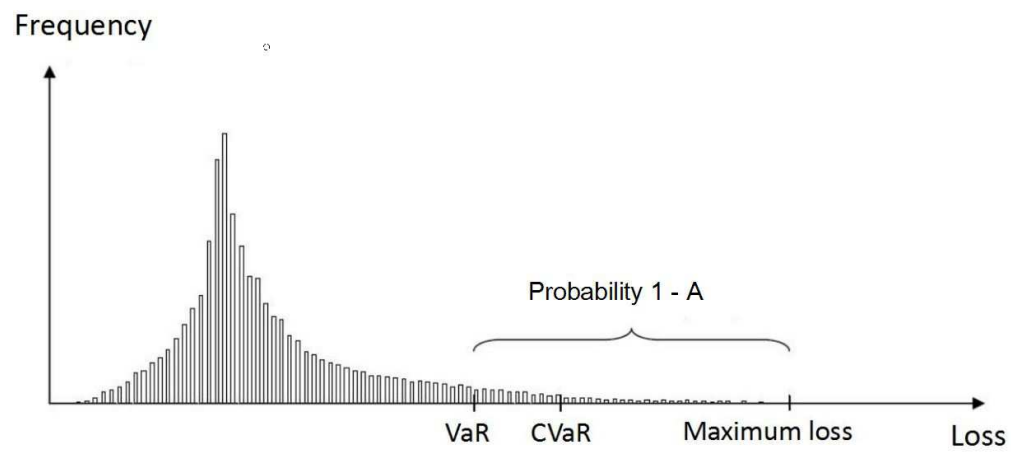

Figure 2: CVaR in relation to VaR

up to the stage of that node. Note that in our nodal formulation the nonanticipativity constraints are incorporated implicitly (i.e., before the scenario tree branches), and therefore we do not know at which node we will be at the next stage. A path in the tree from the root (i.e., first-stage) node to a node at the last stage represents a scenario.

The consumer's decision sequence is as follows. At stage 1, the consumer chooses how many monthly and week-1 electricity and gas futures it purchases. At stage 2, the consumer observes the realised spot prices for week 1. Depending on how much electricity and gas it purchased from the futures markets, it then decides, for each subperiod of week 1 , how much electricity and gas to purchase on the spot markets, how much electricity to produce on-site, and whether to meet the heat demand using the boiler or heat recovery. While there are no monthly futures purchases at stages $2-5$, the weekly futures and spot decision-making procedure is repeated analogously for the remaining three weeks. Finally, as this paper concerns only the operational decisions of a consumer, we disregard the investment costs of the on-site generation units as sunk costs will not affect generation and hedging decisions. 


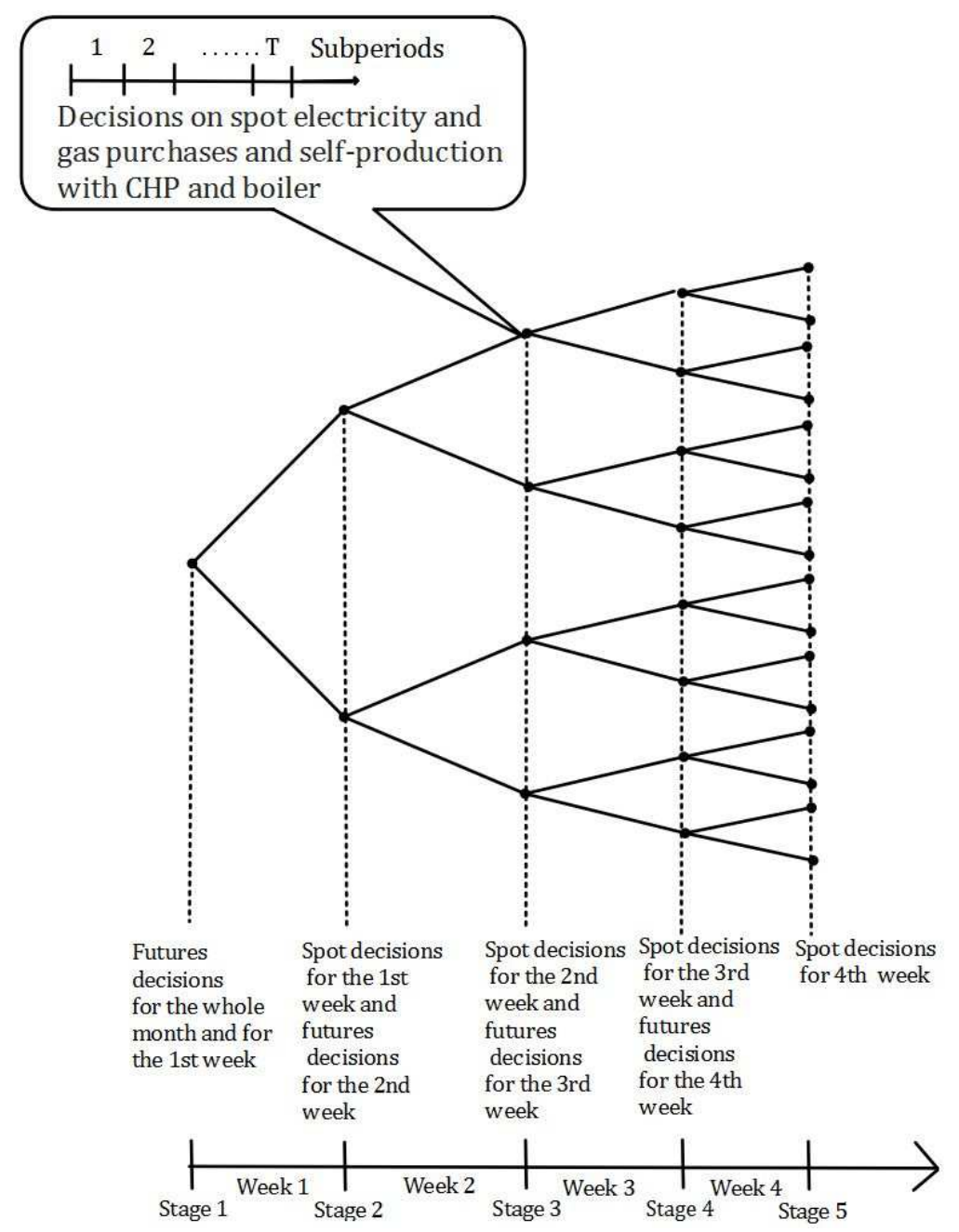

Figure 3: Scenario tree

\subsection{Model formulation}

\subsubsection{Objective function}

The objective function in Eq. (1) minimises the sum of the expected value and a weighted CVaR of the operational cost of running the DG system:

$$
\text { minimise } \sum_{s \in \mathcal{S}} q_{s} \gamma_{s}+B\left(\xi+\frac{1}{1-A} \sum_{s \in \mathcal{S}} q_{s} \eta_{s}\right)
$$


Note that as $B$ increases to the point that all hedging options are fully utilised, the bi-objective function in Eq. (1) collapses to one of pure risk minimisation.

\subsubsection{Constraints}

Eqs. (2)-(3) are necessary for calculating the CVaR of the cost of running the DG system up to the end of the time horizon, $\forall s \in \mathcal{S}$ :

$$
\begin{gathered}
\gamma_{s}-\xi-\eta_{s} \leq 0 \\
\eta_{s} \geq 0
\end{gathered}
$$

Eq. (4) calculates the cost of running the DG system in scenario $s \in \mathcal{S}$ :

$$
\begin{aligned}
& \gamma_{s}=\sum_{n \in \mathcal{N}_{s} \backslash\{1\}} \sum_{t \in \mathcal{T}}\left(\sum_{c \in \mathcal{C}}\left(z_{c}^{e} L_{c}^{e} H_{c, w(n), t}+y_{c, a(n)}^{\mathrm{e}} F_{a(n)}^{e} H_{c, w(n), t}\right)\right. \\
& \left.+x_{n, t}^{\mathrm{e}} P_{n, t}^{e}+\left(z^{\mathrm{g}}+z^{\mathrm{b}}\right) L^{g} J_{w(n), t}+\left(x_{n, t}^{\mathrm{g}}+x_{n, t}^{\mathrm{b}}\right) P_{n, t}^{g}\right)
\end{aligned}
$$

Eqs. (5)-(6) ensure that the electricity and heat demands are met at all time, $\forall n \in \mathcal{N}_{-1}, \forall t \in \mathcal{T}$ :

$$
\begin{aligned}
& x_{n, t}^{\mathrm{e}}+\sum_{c \in \mathcal{C}}\left(y_{c, a(n)}^{\mathrm{e}} H_{c, w(n), t}+z_{c}^{\mathrm{e}} H_{c, w(n), t}\right) \\
& +E^{e}\left(x_{n, t}^{\mathrm{g}}+z^{\mathrm{g}} J_{w(n), t}\right) \geq D_{w(n), t}^{e} \\
& E^{h} E^{e}\left(x_{n, t}^{\mathrm{g}}+z^{\mathrm{g}} J_{w(n), t}\right) \\
& +E^{b}\left(x_{n, t}^{\mathrm{b}}+z^{\mathrm{b}} J_{w(n), t}\right) \geq D_{w(n), t}^{h}
\end{aligned}
$$

Eqs. (7)-(8) ensure that the capacity limits of the electricity generation unit and the boiler are observed, $\forall n \in \mathcal{N}_{-1}, \forall t \in \mathcal{T}$ :

$$
\begin{aligned}
& E^{e}\left(x_{n, t}^{\mathrm{g}}+z^{\mathrm{g}} J_{w(n), t}\right) \leq K^{e} J_{w(n), t} \\
& E^{b}\left(x_{n, t}^{\mathrm{b}}+z^{\mathrm{b}} J_{w(n), t}\right) \leq K^{b} J_{w(n), t}
\end{aligned}
$$

Finally, all of the purchase decision variables must be non-negative, $\forall n \in$ $\mathcal{N}_{-1}, \forall t \in \mathcal{T}, \forall c \in \mathcal{C}:$

$$
\begin{gathered}
x_{n, t}^{\mathrm{e}} \geq 0, x_{n, t}^{\mathrm{g}} \geq 0, x_{n, t}^{\mathrm{b}} \geq 0, y_{c, a(n)}^{\mathrm{e}} \geq 0, \\
z_{c}^{\mathrm{e}} \geq 0, z^{\mathrm{g}} \geq 0, z^{\mathrm{b}} \geq 0
\end{gathered}
$$




\section{Numerical example}

While Germany is one of the largest CHP markets in the world, the share of cogeneration in its electricity production at $14.5 \%$ is still relatively low compared to other European countries, such as the Netherlands and Denmark with a 30\% and a $53 \%$ share, respectively. Germany, with similar weather conditions as the Netherlands and Denmark, has huge potential to increase its CHP generation both in the residential and commercial sectors [31]. Furthermore, additional CHP capacity can also contribute to efficient and more reliable energy supply to counteract the growing intermittent production. Consequently, the German government has set a target to raise the level of electricity produced by CHP to $25 \%$ by 2020 . To examine how operational risk from energy price uncertainties can be managed by a large consumer in Germany, we solve the optimisation problem using German electricity and gas spot and futures prices. By contrast, barriers to CHP adoption in developing countries do not arise from risk aversion because investors typically do not face uncertain energy prices. Instead, distributed generation investment is inhibited primarily by institutional [32] and technical [33] factors such as intellectual property rights and lack of protocols for voltage control, respectively.

\subsection{Spot market data}

The parameters to generate the electricity and gas price scenarios are estimated using data from the European Energy Exchange's (EEX) German electricity and gas spot markets between 1 January 2010 and 2 December 2012 (Fig. 4). We use the hourly electricity spot prices to calculate the daily average peak (8 AM-8 PM) and off-peak (8 PM-8 AM) prices $\left(\hat{P}_{\hat{t}}^{\mathrm{e}}\right)$. By using a daily peak and off-peak $(T=14)$ instead of an hourly $(T=168)$ granularity, we keep our problem tractable while capturing the daily variability of the electricity price.

We assume that electricity prices can be described by a seasonal autoregressive integrated moving average (SARIMA) process because it takes into account the seasonal patterns and periods of volatility that electricity prices typically 

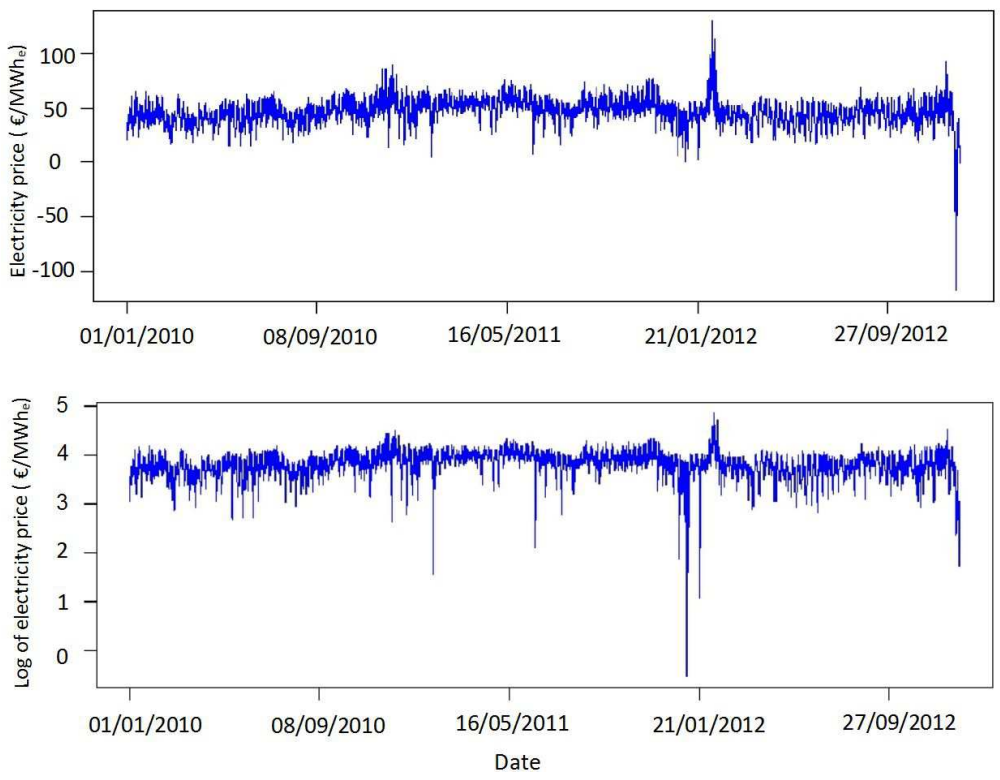

Figure 4: German off-peak and peak load electricity (log) prices

exhibit $[35,36]$. While other models, such as generalised autoregressive conditional heteroscedasticity (GARCH) and reduced-form regime switching [37], may be more appropriate for forecasting, since we are using time-series analysis for risk management, SARIMA models are adequate in this context. In fact, [38] compare linear and non-linear models for electricity and gas prices for the purposes of capturing the value of a gas-fired power plant and demonstrate that the models with the best forecasting performance (both in- and out-of-sample) are not necessarily better in terms of asset valuation.

In SARIMA models, autoregression terms express that the modelled variable depends linearly on its past values, while the moving average terms incorporate the effect of previous error terms. Once we decide how many seasonal, autoregressive, and moving average terms to use, we fit the model using the maximum likelihood function with starting values minimising the conditional sum of squared errors [34]. SARIMA models can be substantially large in terms of the number and combination of terms. Thus, we estimate the number of (seasonal and non-seasonal) autoregressive and moving average terms iter- 
atively by comparing the Akaike information criterion [36], and we find that the following SARIMA process provides the best fit to the electricity prices $\hat{P}_{\hat{t}}^{\mathrm{e}}, \hat{t} \in \hat{\mathcal{T}}:=\{1, \ldots, T \cdot W\}:$

$$
\begin{gathered}
\left(1-\phi_{1}-\phi_{2}-\phi_{3}\right)\left(1-\Phi_{1} B^{14}\right)(1-B)\left(1-B^{14}\right) \hat{P}_{\hat{t}}^{\mathrm{e}}= \\
\left(1+\theta_{1}+\theta_{2}+\theta_{3}+\theta_{4}\right)\left(1+\Theta_{1} B^{14}+\Theta_{2} B^{15}\right) \epsilon_{\hat{t}}^{\mathrm{e}}
\end{gathered}
$$

Here, we apply the backshift operator $B^{k}$ to specify lagged prices, i.e., $B^{k} \hat{P}_{\hat{t}}^{\mathrm{e}}=$ $\hat{P}_{\hat{t}-k}^{\mathrm{e}}$, and we assume that $\epsilon_{\hat{t}}^{\mathrm{e}}, \hat{t} \in \hat{\mathcal{T}}$, are independent and identically distributed normal random variables with zero mean and constant standard deviation, $\sigma^{\mathrm{e}}$. The parameters of process (10) are given in Table 1. Both the autocorrelation and partial autocorrelation functions demonstrate that the peak and off-peak electricity prices exhibit strong weekly seasonality (Figs. 5-6), which equals to a 14-period seasonality. As Fig. 7 shows, the selected model results in residuals that are approximately white noise.

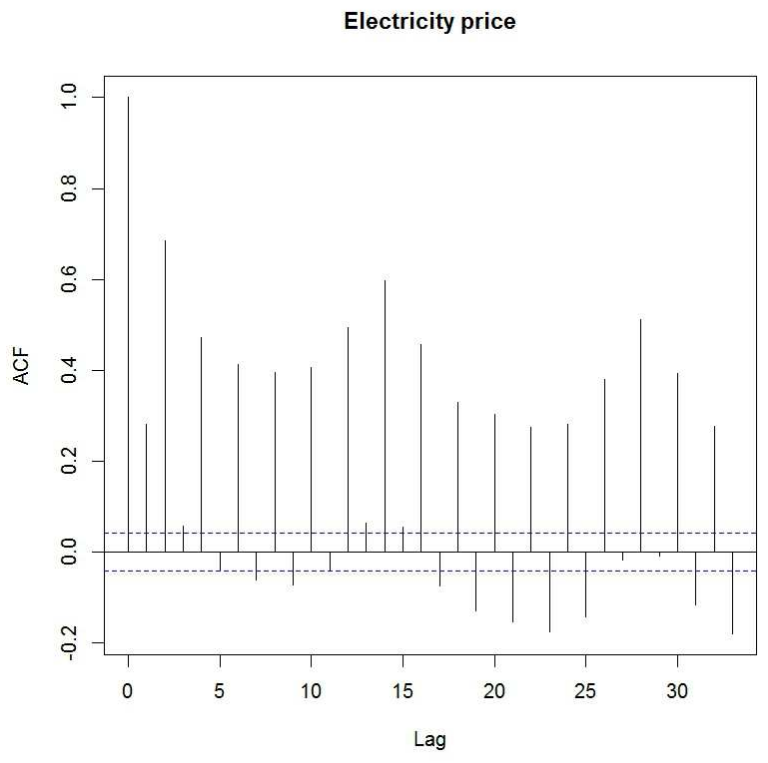

Figure 5: Autocorrelation function of electricity price

The gas price $\left(\tilde{P}_{\tilde{t}}^{\mathrm{g}}\right)$ is assumed to follow a dynamic regression process de- 


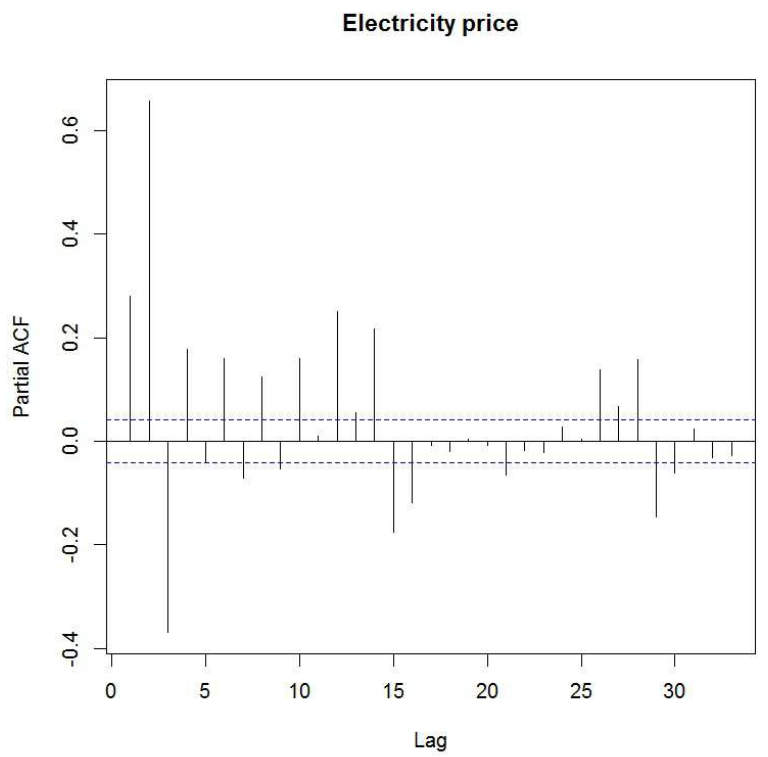

Figure 6: Partial autocorrelation function of electricity price

pendent on the generated electricity price. Since gas spot prices have a daily granularity, we calculate the daily electricity price using the average of the respective peak and off-peak prices, $\forall \tilde{t} \in \tilde{\mathcal{T}}:=\left\{1, \ldots, \frac{T}{2} \cdot W\right\}$ :

$$
\tilde{P}_{\tilde{t}}^{\mathrm{e}}=\frac{\hat{P}_{2 \tilde{t}-1}^{\mathrm{e}}+\hat{P}_{2 \tilde{t}}^{\mathrm{e}}}{2} \text {. }
$$

The best fit to the daily gas spot prices $\tilde{P}_{\tilde{t}}^{\mathrm{g}}, \tilde{t} \in \tilde{\mathcal{T}}$, is the following dynamic regression model:

$$
\begin{gathered}
\tilde{P}_{\tilde{t}}^{\mathrm{g}}=\zeta+\mu_{1} \tilde{P}_{\tilde{t}-1}^{\mathrm{g}}+\mu_{4} \tilde{P}_{\tilde{t}-4}^{\mathrm{g}}+\mu_{6} \tilde{P}_{\tilde{t}-6}^{\mathrm{g}} \\
+\psi \tilde{P}_{\tilde{t}}^{\mathrm{e}}+\psi_{3} \tilde{P}_{\tilde{t}-3}^{\mathrm{e}}+\psi_{5} \tilde{P}_{\tilde{t}-5}^{\mathrm{e}}+\epsilon_{\tilde{t}}^{\mathrm{g}}
\end{gathered}
$$

where we assume that $\epsilon_{\tilde{t}}^{\mathrm{g}}, \tilde{t} \in \tilde{\mathcal{T}}$, are mutually independent and identically distributed normal random variables with zero mean and constant standard deviation, $\sigma^{\mathrm{g}}$, and independent from $\epsilon_{\hat{t}}^{\mathrm{e}}, \hat{t} \in \hat{\mathcal{T}}$. The estimated parameters of process (12) are displayed in Table 1. 


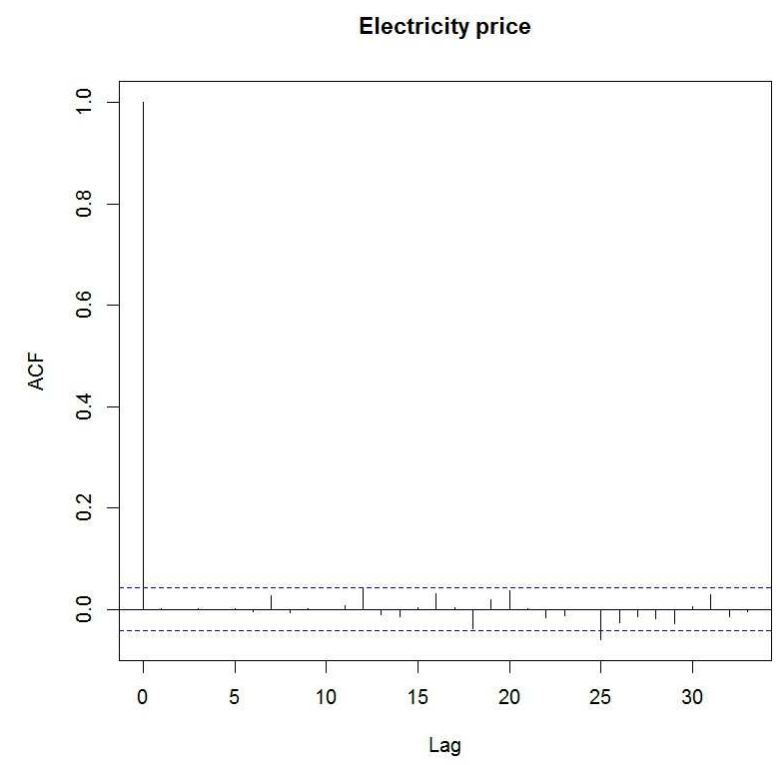

Figure 7: Autocorrelation function of residuals

For our numerical example, we build a scenario tree with seven branches per non-terminal node, resulting in a total of $S=2401$ scenarios. We demonstrate that seven branches is adequate for our purposes by solving the problem of a risk-neutral consumer repeatedly for an increasing branching factor (i.e., number of branches per non-terminal node). For each branching factor, the problem is solved for ten statistically independent scenario trees. Fig. 8 shows the average and the $10 \%$ and $90 \%$ quantiles of the optimal objective value. For a branching factor of seven, the optimal value estimator exhibits a high degree of precision, manifested by the narrow empirical confidence interval. Therefore, we conclude that a branching factor of seven is an appropriate choice for ensuring results stability.

In order to build the scenario tree, we sample $S$ electricity price paths $\left\{\hat{P}_{s, \hat{t}}^{\mathrm{e}}\right\}_{\hat{t} \in \hat{\mathcal{T}}}, s \in \mathcal{S}:=\{1, \ldots, S\}$, from process (10) and corresponding $S$ gas price paths $\left\{\tilde{P}_{s, \tilde{t}}^{\mathrm{g}}\right\}_{\tilde{t} \in \tilde{\mathcal{T}}}, s \in \mathcal{S}$, from process (12). These scenario paths are then used to construct the scenario tree according to the following relations, 
$\forall t \in \mathcal{T}, \forall s \in \mathcal{S}, \forall n \in \mathcal{N}_{s} \backslash\{1\}:$

$$
\begin{aligned}
& P_{n, t}^{\mathrm{e}}=\hat{P}_{s, t+T[w(n)-2]}^{\mathrm{e}} \\
& P_{n, t}^{\mathrm{g}}= \begin{cases}\tilde{P}_{s, \frac{t}{2}+\frac{T}{2}[w(n)-2]}^{\mathrm{g}} & \text { if } t \text { is even } \\
\tilde{P}_{s, \frac{t+1}{2}+\frac{T}{2}[w(n)-2]}^{\mathrm{g}} & \text { if } t \text { is odd }\end{cases}
\end{aligned}
$$

Note that, while we generate gas prices for $\frac{T}{2} \cdot W$ periods, the scenario tree contains $T \cdot W$ time periods. For this reason, Eq. (14) assigns the same gas price to consecutive peak and off-peak periods. Furthermore, to obtain a valid scenario tree, electricity and gas prices at a given time period, but in different scenarios $s$ and $s^{\prime}$ have to be equal if they share the same history of observations. In other words, the relations $\hat{P}_{s, \hat{t}}^{\mathrm{e}}=\hat{P}_{s^{\prime}, \hat{t}}^{\mathrm{e}}\left(\tilde{P}_{s, \tilde{t}}^{\mathrm{g}}=\tilde{P}_{s^{\prime}, \tilde{t}}^{\mathrm{g}}\right)$ must be enforced if scenarios $s$ and $s^{\prime}$ pass through the same nodes up to and including the stage of time period $\hat{t} \in \hat{\mathcal{T}}(\tilde{t} \in \tilde{\mathcal{T}})$.

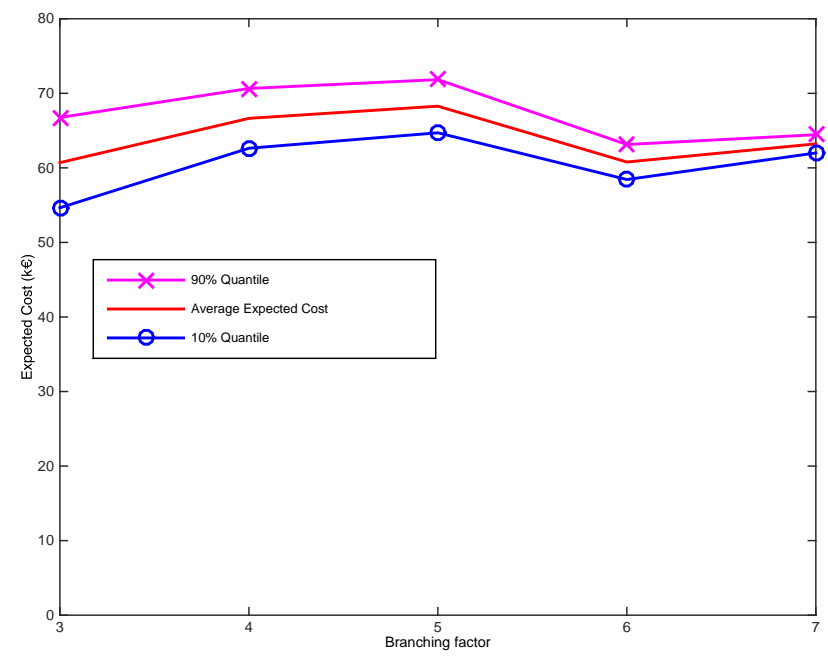

Figure 8: Average expected cost and quantiles as a function of the branching factor

\subsection{Futures market data}

One of the main requirements for price scenario generation is to ensure an arbitrage-free pricing environment [39], i.e., it is not possible to decrease both 
Table 1: Estimated process parameters for electricity and gas prices

\begin{tabular}{ll}
\hline \hline$\phi_{1}=-0.7612$ & $\theta_{3}=-0.1612$ \\
$\phi_{2}=0.4368$ & $\theta_{4}=-0.1584$ \\
$\phi_{3}=0.2010$ & $\Theta_{1}=-0.0897$ \\
$\Phi_{1}=-0.8610$ & $\Theta_{2}=-0.8714$ \\
$\theta_{1}=0.2168$ & $\sigma^{\mathrm{e}}=43.40$ \\
$\theta_{2}=-0.7014$ & \\
\hline \hline$\zeta=0.5820$ & $\psi=0.0183$ \\
$\mu_{1}=0.9397$ & $\psi_{3}=-0.0106$ \\
$\mu_{4}=-0.8830$ & $\psi_{5}=-0.0126$ \\
$\mu_{6}=0.1343$ & $\sigma^{\mathrm{g}}=0.8206$ \\
\hline \hline
\end{tabular}

the CVaR and expected cost at the same time by purchasing futures. Thus, to maintain the no-arbitrage principle, we calculate the gas and electricity futures prices using the corresponding average spot prices and risk premia as follows, for all $c \in \mathcal{C}$ and all non-terminal nodes $n \in \mathcal{N}$ :

$$
\begin{aligned}
F_{c, n}^{e} & =\left(\frac{1}{\left|\mathcal{D}_{n}\right|} \sum_{n^{\prime} \in \mathcal{D}_{n}} \frac{1}{\left|\mathcal{T}_{c}\right|} \sum_{t \in \mathcal{T}_{c}} P_{n^{\prime}, t}^{e}\right)\left(1+\Pi_{w, c}^{\mathrm{e}}\right) \\
L_{c}^{e} & =\left(\frac{1}{\left|\mathcal{N}_{-1}\right|} \sum_{n \in \mathcal{N}_{-1}} \frac{1}{\left|\mathcal{T}_{c}\right|} \sum_{t \in \mathcal{T}_{c}} P_{n, t}^{e}\right)\left(1+\Pi_{m, c}^{\mathrm{e}}\right) \\
L^{g} & =\left(\frac{1}{\left|\mathcal{N}_{-1}\right|} \sum_{n \in \mathcal{N}_{-1}} \frac{1}{|\mathcal{T}|} \sum_{t \in \mathcal{T}} P_{n, t}^{g}\right)\left(1+\Pi_{m}^{\mathrm{g}}\right)
\end{aligned}
$$

The risk premia for gas and electricity futures are calculated from the EEX Phelix and Natural Gas Futures markets data and the corresponding spot prices from the 2011-2012 period (Table 2). Note that, in accordance with the Phelix market, only monthly electricity futures have off-peak load profiles.

\subsection{Demand data}

For our numerical example, we consider a small hospital that needs to meet its own energy demands and has no commercial orientation. The hospital manager aims to either minimise expected costs and/or manage risk and assesses how CHP contributes to this end without considering the possibility of selling electricity to the main grid. Since building-level energy loads can be forecasted with accuracy [40], we assume that the hospital's electricity and heat loads are 
deterministic. The loads used in this paper are based on a typical winter energy consumption of a small hospital provided by the Energy Systems Research Unit at the University of Strathclyde (Fig. 9). Each period refers to a twelve-hour block (either peak or off-peak) during a day corresponding to the nature of electricity prices as indicated in Section 4.1. Thus, there are $7 \times 2=14$ time periods per week, which becomes $4 \times 14=56$ periods per month.

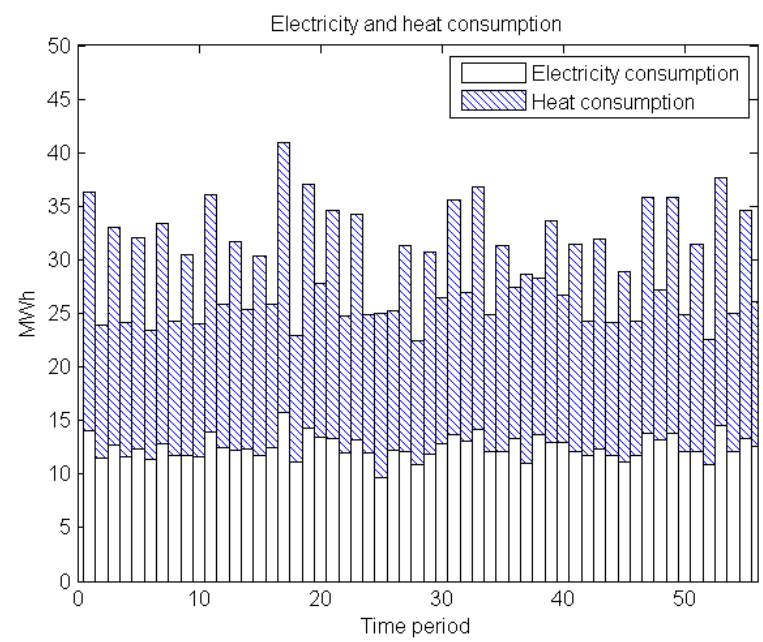

Figure 9: Electricity and heat consumption

Table 2: Risk premia for futures

\begin{tabular}{ll}
\hline \hline$\Pi_{m, b}^{\mathrm{e}}=0.021$ & $\Pi_{w, b}^{\mathrm{e}}=0.009$ \\
$\Pi_{m, o}^{\mathrm{e}}=0.020$ & $\Pi_{w, p}^{\mathrm{e}}=0.041$ \\
$\Pi_{m, p}^{\mathrm{e}}=0.083$ & $\Pi_{m}^{\mathrm{g}}=0.004$ \\
\hline \hline
\end{tabular}

\subsection{Technology data}

We compare the energy procurement problem with no on-site generation, with on-site generation without heat recovery (MT), and with on-site generation with heat recovery $(\mathrm{CHP})$. The electrical conversion efficiency $\left(E^{e}\right)$ of the 
microturbines is $35 \%$, and the CHP's heat-recovery rate $\left(E^{e} \cdot E^{h}\right)$ is $52.5 \%$, while the boiler's conversion efficiency $\left(E^{b}\right)$ is $90 \%$. These parameters are in line with [7], [8], and [19]. Finally, we consider on-site generation at $300 \mathrm{~kW}_{\mathrm{e}}$, $600 \mathrm{~kW}_{\mathrm{e}}$, and $900 \mathrm{~kW}_{\mathrm{e}}$ capacity levels.

\section{Results}

\subsection{Main insights}

The optimisation problems are implemented in the General Algebraic Modeling System (GAMS) and solved using the GUROBI solver on a Windows workstation with an Intel Core i7 3.3GHz CPU and 16 GB RAM. The computational times range from 13 to 278 seconds. Our results support previous findings that, compared to purchasing electricity from the main grid, on-site generation with CHP reduces significantly the consumer's expected energy cost, contributes to higher energy efficiency, and, hence, to lower $\mathrm{CO}_{2}$ emissions. In addition, we find that on-site generation with CHP can decrease the consumer's CVaR and, consequently, can function as a physical hedge against financial risk. Using on-site generation reduces both the expected running cost of the consumer and its CVaR (Table 3). While higher installed capacity results in lower expected cost for both CHP and MT, interestingly, the $300 \mathrm{~kW}_{\mathrm{e}}$ CHP unit reduces the expected cost more than even the $900 \mathrm{~kW}_{\mathrm{e}} \mathrm{MT}$ unit.

Figs. 10 and 11 present the histograms of the cost savings compared to no on-site generation for each scenario. The distributions of the cost reduction with MT are right-skewed with similar central tendencies, whereas with CHP, the distributions of the cost reduction are close to symmetric and the median saving increases significantly with larger capacity. Thus, with MT, a lower cost reduction is much more likely than with CHP, the use of which can result in small and large cost reductions with similar probabilities.

In terms of CVaR reduction, the difference between MT and CHP is even more pronounced. First, note that the CVaR of the consumer can be decreased either by reducing the expected cost or by reducing the volatility of the cost of 
Table 3: Results for running the distributed generation under risk-neutral regime $(B=0)$

\begin{tabular}{|l|c|c|l|l|}
\hline Case & $\begin{array}{l}\text { Expected } \\
\text { cost }(\mathrm{k} €)\end{array}$ & $\begin{array}{l}\mathrm{CVaR} \\
(\mathrm{k} €)\end{array}$ & $\begin{array}{l}\text { Expected } \\
\text { energy } \\
\text { efficiency }\end{array}$ & $\begin{array}{l}\text { Expected } \\
\mathrm{CO}_{2} \text { emis- } \\
\text { sions } \\
\text { (kiloton) }\end{array}$ \\
\hline No on-site generation & 79.6 & 86.8 & $71.2 \%$ & 0.92 \\
\hline $300 \mathrm{~kW}_{\mathrm{e}} \mathrm{MT}$ & 78.7 & 86.0 & $69.1 \%$ & 0.69 \\
\hline $600 \mathrm{~kW}_{\mathrm{e}} \mathrm{MT}$ & 77.9 & 85.2 & $67.1 \%$ & 0.86 \\
\hline $900 \mathrm{~kW}_{\mathrm{e}} \mathrm{MT}$ & 77.0 & 84.6 & $65.2 \%$ & 0.83 \\
\hline $300 \mathrm{~kW}_{\mathrm{e}} \mathrm{CHP}$ & 71.8 & 78.3 & $75.1 \%$ & 0.77 \\
\hline $600 \mathrm{~kW}_{\mathrm{e}} \mathrm{CHP}$ & 64.0 & 70.0 & $79.5 \%$ & 0.62 \\
\hline $900 \mathrm{~kW}_{\mathrm{e}} \mathrm{CHP}$ & 58.1 & 64.0 & $82.2 \%$ & 0.50 \\
\hline
\end{tabular}

running the DG. While MT reduces the CVaR at each capacity level, the CVaR reductions are, in fact, smaller than the reduction in expected cost, i.e., the CVaR relative to the expected cost is increasing. On the contrary, CHP always results in a larger CVaR reduction than the reduction in expected cost. As the standard deviation of the gas spot price is lower than that of the electricity spot price $-4.7 \%$ compared to $25.0 \%$ - the CHP reduces the CVaR of the consumer by efficiently swapping electricity for gas. To generate one $\mathrm{MWh}_{\mathrm{e}}$ of electricity, both MT and CHP require 2.8 MWh gas, but the CHP unit recovers 1.5 MWh heat at the same time, thereby reducing the consumer's gas purchases. Since heat consumption is on average $60 \%$ higher than the electricity consumption in peak periods, and only $6 \%$ larger in off-peak periods, the consumer uses CHP the most when the electricity price is more volatile. Thus, the CHP not only needs to swap less gas for a $\mathrm{MWh}_{\mathrm{e}}$ of electricity but also does this in periods with more volatile electricity prices. This is why the reduction in relative standard deviation for each scenario is much lower with MT (Fig. 12) than with CHP (Fig. 13). Due to the high level of heat consumption in peak periods, operating CHP units with larger capacity size results, on average, in a higher level of 


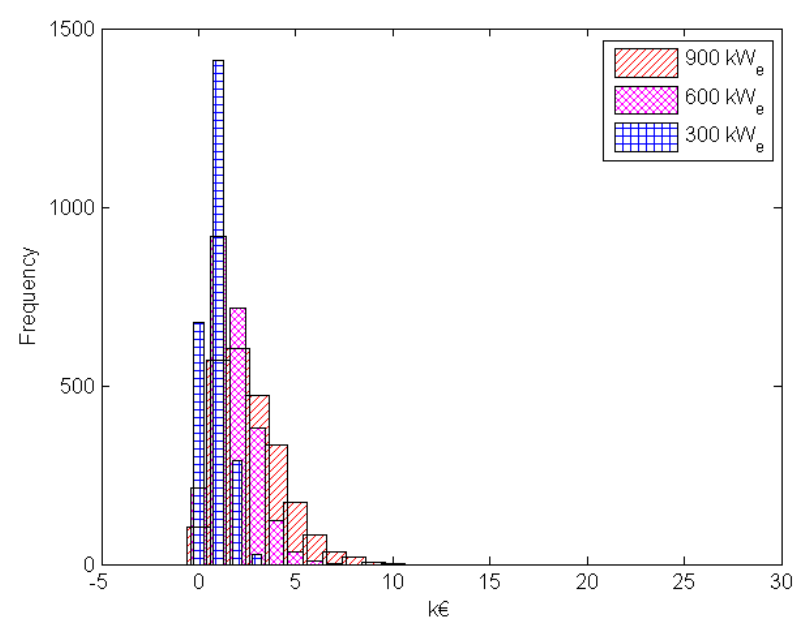

Figure 10: Cost savings with MT compared to no on-site generation

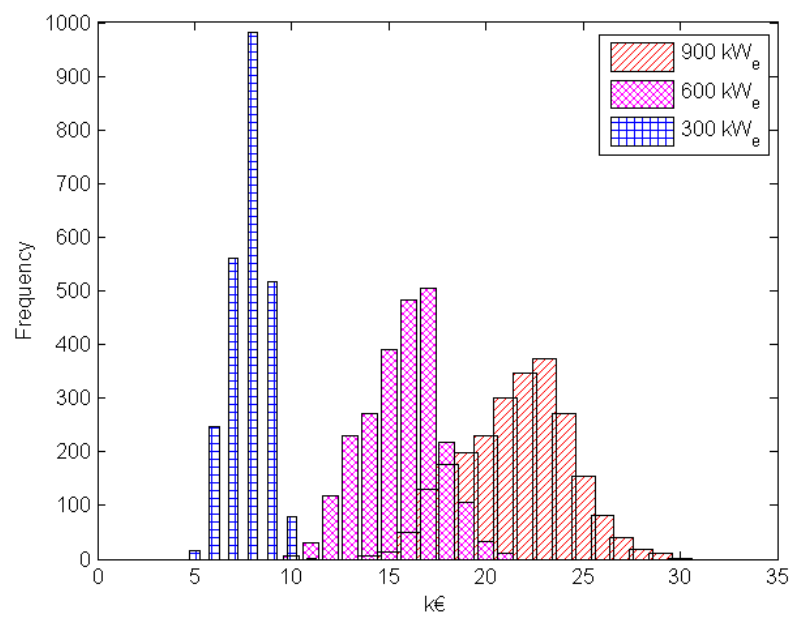

Figure 11: Cost savings with CHP compared to no on-site generation

reduction in relative standard deviation.

\subsection{On-site generation with futures}

To examine further the risk-reducing characteristics of on-site generation, we run the consumer's optimisation model with a $600 \mathrm{~kW}_{\mathrm{e}} \mathrm{MT}$ or CHP unit together with the option of purchasing electricity and gas futures. We find a strong interaction between on-site generation and financial hedges, i.e., the type 


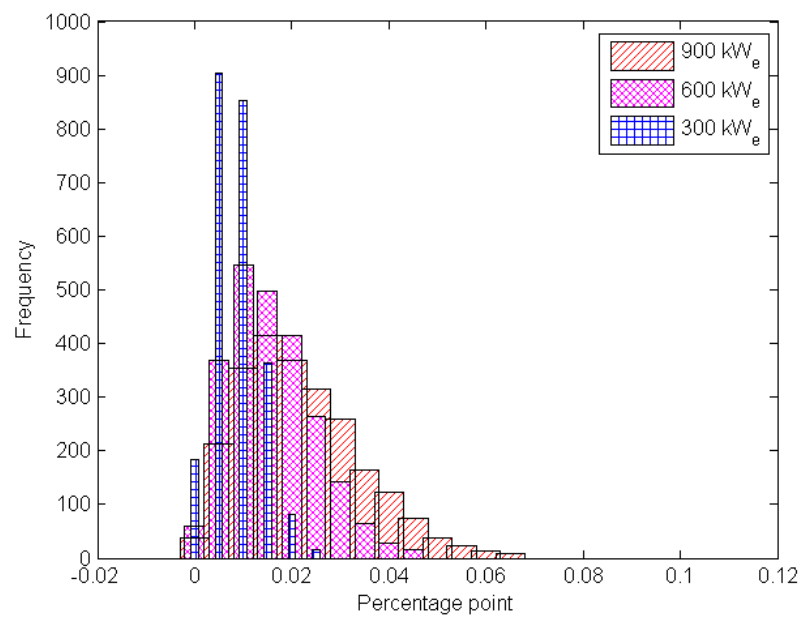

Figure 12: Reduction in relative standard deviation with MT compared to no on-site generation

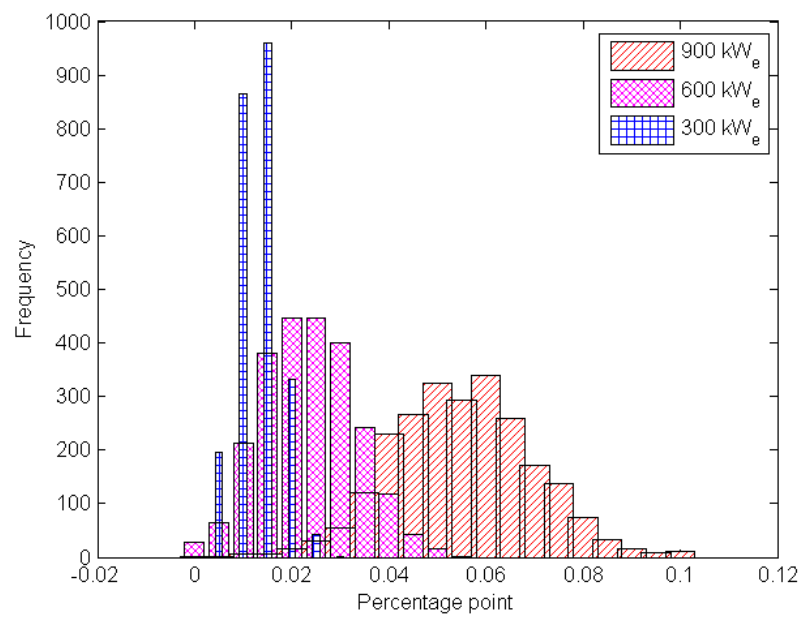

Figure 13: Reduction in relative standard deviation with CHP compared to no on-site generation

of on-site generation determines which futures the consumer purchases. Fig. 14 shows the efficient frontiers of a consumer with only futures purchases, with MT installation and futures purchases, and with CHP installation and futures 
purchases. These frontiers are delimited by varying the $B$ parameter in order to illustrate the mean-risk tradeoff. First, note that on-site generation with MT on its own (at $B=0$ ) has a higher CVaR than a risk-averse consumer with only futures purchases (at $B=0.2$ ), thereby indicating that financial futures are more efficient hedges than an MT. While electricity futures fix the electricity price and can eliminate price volatility, a DG system with MT requires spot gas purchases at a variable price. Although the volatility of gas spot price is much lower than that of the electricity spot price, because of the low total MT efficiency, the consumer needs to purchase more spot gas, which results in a higher CVaR compared to purchasing only futures. Conversely, a DG system with a CHP unit achieves a much lower CVaR than the most risk-averse consumer that buys only futures. In addition, financial futures are more efficient at reducing CVaR together with CHP, i.e., they have a lower mean-CVaR tradeoff, which is shown by the flatter efficient frontier.

Considering the consumer with only financial hedges, Fig. 15a indicates that the more risk averse the consumer becomes, the more monthly base load futures it purchases. For relatively low values of $B$, the consumer initially uses weekly base load futures (Fig. 15b). In the most risk-averse regime at $B=10$, the consumer's CVaR reduction amounts to $€ 4.9 \mathrm{k}$, which is $5.6 \%$ of the CVaR at the risk-neutral regime at $B=0$. The reason why the consumer mostly purchases base load contracts is that the hospital's electricity consumption differs only slightly between peak and off-peak periods. Thus, purchasing monthly electricity base load futures, which have lower risk premia than monthly peak load contracts and just slightly higher risk premia than monthly off-peak contracts, provides a cheaper hedge. Similarly, with increasing risk aversion, the consumer purchases more monthly gas futures for the boiler. At its maximum level of risk aversion $(B=10)$, the consumer meets $73.7 \%$ of its heat demand through monthly gas contracts (Fig. 16a), which overtakes spot gas purchases at even low values of $B$ (Fig. 16b).

In comparison to a consumer with only futures trading, for a risk-averse consumer with an MT unit, the share of monthly base load electricity futures de- 


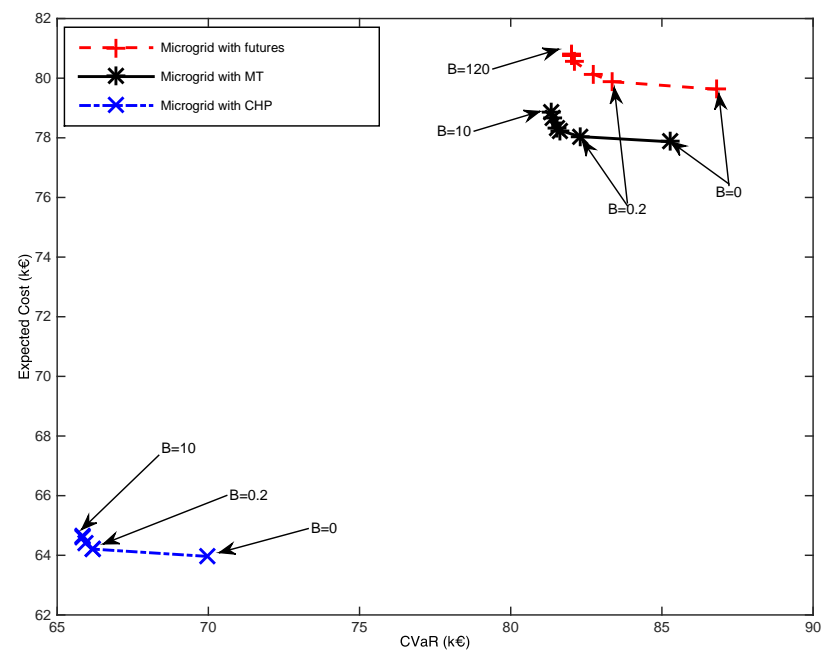

Figure 14: Efficient frontiers with futures purchases

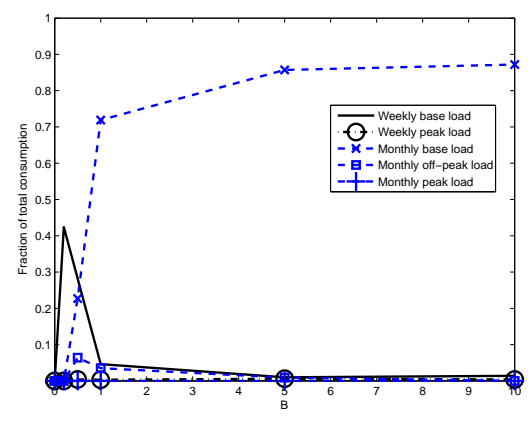

(a) $B \geq 0$

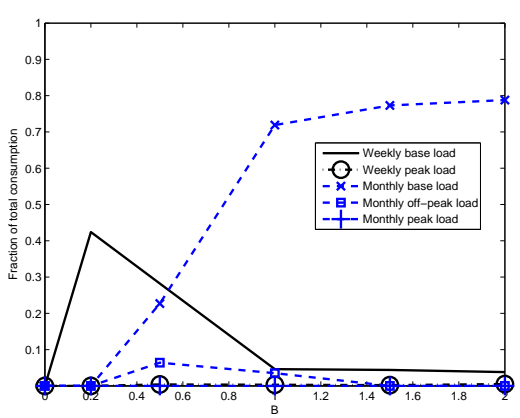

(b) $0 \leq B \leq 2$

Figure 15: Electricity consumption without on-site generation

creases significantly and is only non-negligible with higher levels of risk aversion (Fig. 17a). The consumer meets on average $20 \%$ of its electricity consumption with on-site generation using gas spot. With risk aversion, the share of off-peak monthly futures and weekly base load futures in electricity consumption first increases and later slightly decreases, which can be seen more clearly in Fig. 17b. This indicates that monthly base load futures are substitutes for weekly base load and monthly off-peak load electricity futures. Furthermore, the share 
of on-site generation with spot gas also decreases slightly from $19.2 \%$ at $B=0$ to $16.5 \%$ at $B=10$. Thus, the consumer uses its MT well below its capacity limit, which would be $62.5 \%$ on average, and, in order to decrease its CVaR, it has to operate the MT less. As using the MT has a negative effect on the consumer's CVaR, it purchases electricity futures with the lowest risk premia, such as weekly base load and monthly off-peak load contracts. Since a consumer with MT can use only the boiler to meet its heat demand, its heat consumption is the same as with no on-site generation, i.e., monthly gas futures purchases increase with risk aversion (Fig. 16a).

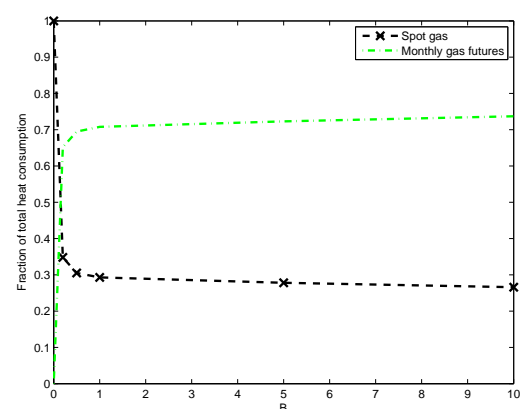

(a) $B \geq 0$

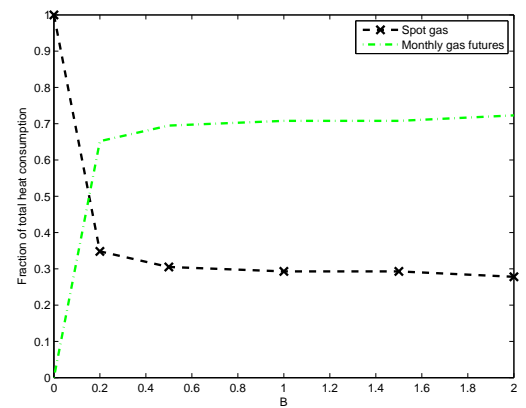

(b) $0 \leq B \leq 2$

Figure 16: Heating consumption with only available futures

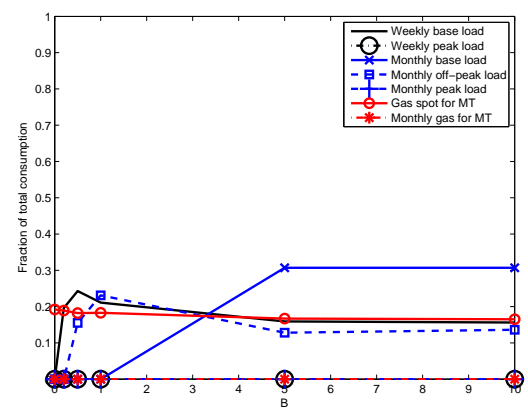

(a) $B \geq 0$

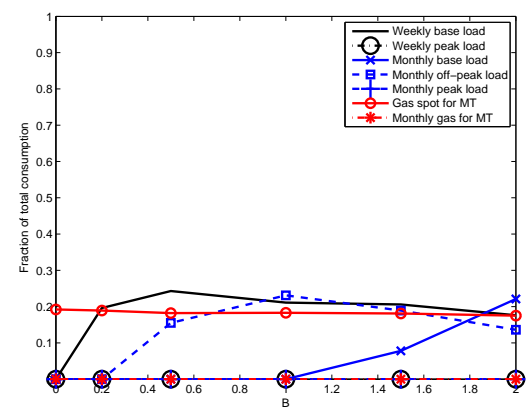

(b) $0 \leq B \leq 2$

Figure 17: Electricity consumption with MT

Finally, Fig. 18a shows the share of on-site generation and futures purchases 
in the electricity consumption of a DG system with an installed CHP unit. The presence of CHP increases the demand for monthly gas futures significantly. An MT unit with lower energy efficiency cannot use monthly gas contracts due to their higher prices, which would negate its achievable cost reduction. A DG system with a CHP unit, on the other hand, can tolerate the risk premia, and with fixed gas prices, it attains greater $\mathrm{CVaR}$ reduction. In fact, the total share of on-site generation with CHP increases from $56.3 \%$ at $B=0$ to $57.7 \%$ at $B=10$. Thus, the CVaR-reducing demand for both gas futures and on-site generation with CHP increases at the same time, which indicates that they are complements. Compared to running an MT unit, the consumer with CHP purchases almost no off-peak monthly and weekly base load electricity futures, and slightly less monthly base load futures. As CHP decreases the consumer's CVaR on its own, the scope for CVaR reduction from electricity futures is much lower. The consumer purchases first mostly weekly electricity base load contracts (Fig. 18b) and then only monthly electricity base load futures in a considerable amount since, as Fig. 15a indicates, these futures can be used the most efficiently to reduce the consumer's CVaR when the $600 \mathrm{~kW}_{\mathrm{e}} \mathrm{CHP}$ unit is not enough to meet all electricity demand. Still, the share of electricity futures is much lower compared to the one of the consumer with no on-site generation or with an MT unit, thereby indicating that on-site generation with CHP and electricity futures are substitutes. As a result of the high share of on-site generation, on average $64.6 \%$ of the consumer's heat consumption is met through heat recovery. In the most risk-averse regime at $B=10$, the consumer's CVaR reduction amounts to $€ 4.1 \mathrm{k}$ which is $5.9 \%$ of the CVaR at the risk-neutral regime $(B=0)$. This is slightly higher in relative terms than the maximum CVaR reduction in a DG system with no on-site generation, which indicates that gas futures are more efficient in reducing CVaR when used with CHP. 


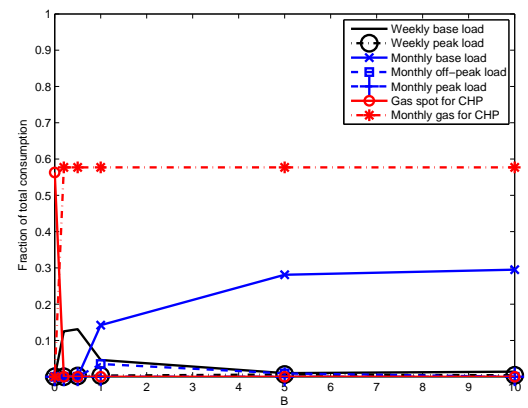

(a) $B \geq 0$

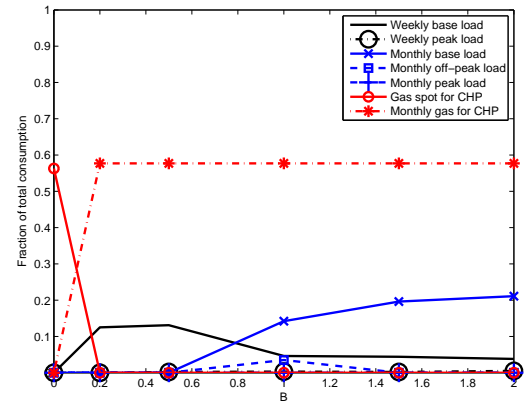

(b) $0 \leq B \leq 2$

Figure 18: Electricity consumption with CHP

\section{Conclusion}

With growing demand for cheap and reliable electricity, DG is likely to play a vital role in the future energy industry. In accordance with previous studies, our results show that a consumer with an installed CHP unit can, indeed, contribute to energy savings and lower $\mathrm{CO}_{2}$ emissions. To encourage customer adoption, numerous initiatives and subsidy schemes have been introduced by the EU and its member states. However, the development of the DG and CHP sectors has been slower than expected. One of the possible reasons for this is the financial uncertainty associated with operating on-site generation due to deregulated energy markets. Barriers to CHP adoption that are not directly covered in our work include inconsistent interconnection standards and disincentives for utilities to promote energy efficiency because their revenues depend on the amount of energy sold [41].

We present a multi-stage stochastic mean-risk optimisation model that can be used to reduce a consumer's risk exposure through on-site generation and electricity and gas futures purchases. By applying this model to a hypothetical hospital, we find that on-site generation, either with MT or with CHP, can reduce the expected operational cost of energy procurement. However, the reduction in expected cost with MT without heat recovery is minimal, and 
the consumer's CVaR relative to its expected cost is larger than without on-site generation. In contrast, a consumer with CHP can lower its expected cost significantly, on average 8.7-fold more than with MT, and can reduce the consumer's CVaR both in absolute terms and relative to its expected cost. Furthermore, when the consumer has access to futures markets, we find that monthly gas futures and on-site generation with CHP exhibit complementarity, i.e., the presence of gas futures increases the demand of a risk-averse consumer for on-site generation. Therefore, improving gas futures market liquidity can contribute to customer adoption of DG. On the other hand, we find that electricity futures are substitutes for on-site generation. Thus, in contrast to the extant literature, we provide a risk-management strategy for improving the viability of CHP as well as policy insights regarding access to liquid futures market. In this work, we disregard the possibility of energy storage or selling electricity on the market, which we would like to explore in a future study.

\section{Acknowledgements}

We are grateful to the EEX Group for provision of German electricity and natural gas price data. Maurovich-Horvat acknowledges the support of the UCL Centre in Financial Computing. Rocha and Siddiqui are grateful for support from the EC FP7 EnRiMa project (number 260041). Feedback from three anonymous referees has helped to improve this paper. Any remaining errors are the authors' own.

\section{Nomenclature}

The notation used in this paper is standard in stochastic programming [42].

Sets and indices

$a(n):$ ancestor node of node $n \in \mathcal{N}_{-1}$

$\mathcal{C}:=\{b, o, p\}$ : set of futures contracts in terms of load profile, which can be either base $(b)$, off-peak $(o)$, or peak load $(p)$ 
$\mathcal{D}_{n}$ : descendant nodes of node $n \in \mathcal{N}$

$\mathcal{N}$ : set of nodes in the scenario tree

$\mathcal{N}_{-1}$ : subset of nodes excluding the root node in the scenario tree, i.e., $\mathcal{N}_{-1}:=$ $\mathcal{N} \backslash\{1\}$

$\mathcal{N}_{s}$ : set of nodes that scenario $s \in \mathcal{S}$ passes through

$\mathcal{S}$ : set of scenarios, i.e., $s \in \mathcal{S}$ is a path from the root node $(n=1)$ to a node at the last stage $W+1$

$\mathcal{T}:=\{1, \ldots, T\}:$ set of time periods at each node $n \in \mathcal{N}_{-1}$

$\mathcal{T}_{c}$ : set of time periods with load profile $c \in \mathcal{C}$ at each node $n \in \mathcal{N}_{-1}$

$\hat{\mathcal{T}}:=\{1, \ldots, T \cdot W\}$ : auxiliary set of time periods for electricity spot price scenario generation

$\tilde{\mathcal{T}}:=\left\{1, \ldots, \frac{T}{2} \cdot W\right\}$ : auxiliary set of time periods for gas spot price scenario generation

$\mathcal{W}:=\{1, \ldots, W+1\}:$ set of stages

\section{Random parameters}

$F_{c, a(n)}^{e}:$ price of weekly electricity futures contracts of type $c \in \mathcal{C}$ fixed in node $a(n), n \in \mathcal{N}_{-1}$, for delivery in the coming week $\left(€ / \mathrm{MWh}_{\mathrm{e}}\right)$

$P_{n, t}^{e}$ : spot price of electricity at node $n \in \mathcal{N}_{-1}$ in time period $t \in \mathcal{T}\left(€ / \mathrm{MWh}_{\mathrm{e}}\right)$ $P_{n, t}^{g}:$ spot price of gas at node $n \in \mathcal{N}_{-1}$ in time period $t \in \mathcal{T}(€ / \mathrm{MWh})$

\section{Fixed parameters}

$\epsilon_{\hat{t}}^{e}$ : error term of the ARIMA model for electricity spot prices in time period $\hat{t} \in \hat{\mathcal{T}}\left(€ / \mathrm{MWh}_{\mathrm{e}}\right)$

$\epsilon_{\tilde{t}}^{g}$ : error term of the dynamic regression model for gas spot prices in time period $\tilde{t} \in \tilde{\mathcal{T}}(€ / \mathrm{MWh})$

$\zeta, \mu_{k}, \psi_{k}$ : parameters used in the dynamic regression model for gas spot prices, $k \in \mathbb{N}$

$\theta_{k}, \Theta_{k}, \phi_{k}, \Phi_{k}$ : parameters used in the ARIMA model for electricity spot prices, $k \in \mathbb{N}$

$\Pi_{m, c}^{\mathrm{e}}, \Pi_{w, c}^{\mathrm{e}}$ : risk premia of monthly and weekly electricity futures contracts of 
type $c \in \mathcal{C}$

$\Pi_{m}^{g}$ : risk premium of monthly gas futures contracts

$\sigma^{\mathrm{e}}, \sigma^{\mathrm{g}}$ : standard deviations of the error term of the electricity and gas price processes

$A$ : confidence level for the conditional value-at-risk (CVaR)

$B$ : risk weight

$E^{b}$ : boiler conversion efficiency, i.e., volume of useful heat produced from one MWh of natural gas (MWh/MWh)

$E^{e}$ : electrical conversion efficiency, i.e., volume of electricity produced from one MWh of natural gas $\left(\mathrm{MWh}_{\mathrm{e}} / \mathrm{MWh}\right)$

$E^{h}$ : heat-recovery rate from on-site generation, i.e., volume of useful heat captured while producing one $\mathrm{MWh}_{e}$ of electricity $\left(\mathrm{MWh} / \mathrm{MWh}_{\mathrm{e}}\right)$

$D_{w(n), t}^{e}$ : electricity load in stage $w(n) \in \mathcal{W}, n \in \mathcal{N}_{-1}$, and period $t \in \mathcal{T}\left(\mathrm{MW}_{\mathrm{e}}\right)$ $D_{w(n), t}^{h}$ : heat load in stage $w(n) \in \mathcal{W}, n \in \mathcal{N}_{-1}$, and period $t \in \mathcal{T}$ (MW)

$H_{c, w(n), t}$ : length of energy delivery by a contract of type $c \in \mathcal{C}$ in stage $w(n) \in \mathcal{W}, n \in \mathcal{N}_{-1}$, in period $t \in \mathcal{T}(\mathrm{h})$

$J_{w(n), t}$ : length of time period $t \in \mathcal{T}$ in stage $w(n) \in \mathcal{W}, n \in \mathcal{N}_{-1}(\mathrm{~h})$

$K^{b}$ : capacity of the boiler unit (MW)

$K^{e}$ : capacity of electricity generation unit $\left(\mathrm{MW}_{e}\right)$

$L_{c}^{e}$ : price of monthly electricity futures contracts of type $c \in \mathcal{C}\left(€ / \mathrm{MWh}_{\mathrm{e}}\right)$

$L^{g}$ : price of monthly gas futures contracts $(€ / \mathrm{MWh})$

$\hat{P}_{\hat{t}}^{e}$ : spot price of electricity in time period $\hat{t} \in \hat{\mathcal{T}}$ used for electricity spot price scenario generation; $\hat{P}_{s, \hat{t}}^{e}$ for scenario $s \in \mathcal{S}\left(€ / \mathrm{MWh}_{\mathrm{e}}\right)$

$\tilde{P}_{\tilde{t}}^{e}$ : spot price of electricity in time period $\tilde{t} \in \tilde{\mathcal{T}}$ used for gas spot price scenario generation; $\tilde{P}_{s, \tilde{t}}^{e}$ for scenario $s \in \mathcal{S}\left(€ / \mathrm{MWh}_{\mathrm{e}}\right)$

$\tilde{P}_{\tilde{t}}^{g}$ : spot price of gas in time period $\tilde{t} \in \tilde{\mathcal{T}}$ used for gas spot price scenario generation; $\tilde{P}_{s, \tilde{t}}^{g}$ for scenario $s \in \mathcal{S}(€ / \mathrm{MWh})$

$q_{s}:$ probability of scenario path $s \in \mathcal{S}$

$w(n) \in \mathcal{W}$ : stage of node $n \in \mathcal{N}$ 
Decision variables

$\gamma_{s}$ : cost of satisfying the electricity and heat loads in scenario path $s \in \mathcal{S}(€)$

$\eta_{s}$ : auxiliary variable to estimate the $\mathrm{CVaR}$ in scenario path $s \in \mathcal{S}(€)$

$\xi$ : value-at-risk at confidence level $A(€)$

$x_{n, t}^{\mathrm{b}}$ : gas purchased from the spot market for boiler heat production in node $n \in \mathcal{N}_{-1}$ during period $t \in \mathcal{T}(\mathrm{MWh})$

$x_{n, t}^{\mathrm{e}}$ : electricity purchased on the spot market in node $n \in \mathcal{N}_{-1}$ during period $t \in \mathcal{T}\left(\mathrm{MWh}_{\mathrm{e}}\right)$

$x_{n, t}^{\mathrm{g}}$ : gas purchased on the spot market for on-site electricity generation in node $n \in \mathcal{N}_{-1}$ during period $t \in \mathcal{T}(\mathrm{MWh})$

$y_{c, a(n)}^{\mathrm{e}}$ : electricity delivered by weekly futures of type $c \in \mathcal{C}$ in node $n \in \mathcal{N}_{-1}$ $\left(\mathrm{MW}_{\mathrm{e}}\right)$

$z^{\mathrm{b}}$ : natural gas delivered by monthly futures for boiler heat production during the whole month (MW)

$z_{c}^{\mathrm{e}}$ : electricity delivered by monthly futures of type $c \in \mathcal{C}$ during the whole month $\left(\mathrm{MW}_{\mathrm{e}}\right)$

$z^{\mathrm{g}}$ : natural gas delivered by monthly futures for on-site electricity generation during the whole month (MW)

\section{References}

[1] European Commission, 2011. Energy Roadmap 2050. Communication from the Commission to the European Parliament, the Council, the European Economic and Social Committee and the Committee of the Regions, $\operatorname{COM}(2011) 885$ final, 15 December 2011, Brussels, Belgium. http://eurlex.europa.eu/LexUriServ/LexUriServ.do?uri=COM:2011:0885:FIN:EN:PDF.

[2] Woo, C.K., King, M., Tishler, A., Chow, L.C.H., 2006. Costs of electricity deregulation. Energy 31(6), 747-768. 
[3] Marnay, C., Venkataramanan, G., 2006. Microgrids in the evolving electricity generation and delivery infrastructure. In Power Engineering Society General Meeting, 2006. IEEE.

[4] Graus, W., Worrell, E., 2009. Trend in efficiency and capacity of fossil power generation in the EU. Energy Policy, 37(6), 2147-2160.

[5] Oswald, B.R., 2007. Verlust- und Verlustenergieabschätzung für das 380kV-Leitungsbauvorhaben Wahle - Mecklar, Hannover.

[6] International Energy Agency Statistics, 2011. Energy Statistics and Balances of Non-OECD Countries and Energy Statistics of OECD Countries, and United Nations, Energy Statistics Yearbook, http://data.worldbank.org/indicator/EG.ELC.LOSS.ZS

[7] Moran, A., Mago, P.J., Chamra, L.M., 2008. Thermoeconomic modeling of micro-CHP (micro-cooling, heating, and power) for small commercial applications. International Journal of Energy Research, 32(9), 808-823.

[8] Siddiqui, A.S., Marnay, C., Edwards, J.L., Firestone, R., Ghosh, S., Stadler, M., 2005. Effects of carbon tax on microgrid combined heat and power adoption. Journal of Energy Engineering 131(3), 2-25.

[9] KWK-G (2002). Gesetz für die Erhaltung, Modernisierung und den Ausbau der Kraft-Wärme-Kopplung (BGBl. I S. 1092).

[10] KWK-G (2009). Gesetz zur Förderung der Kraft-Wärme-Kopplung (BGBl. I S. 2101).

[11] KWK-G (2012). Gesetz zur Änderung des Kraft-Wärme-Kopplungsgesetzes (BGBl. I S. 1494).

[12] Streckiene, G., Martinaitis, V., Andersen, A.N., Katz, J., 2009. Feasibility of CHP-plants with thermal stores in the German spot market. Applied Energy, 86(11), 2308-2316. 
[13] European Cogeneration Review - Germany, 2013. Country report by COGEN Europe. Brussels.

[14] Schleich, J., Gruber, E., 2008. Beyond case studies: Barriers to energy efficiency in commerce and the services sector. Energy Economics, 30(2), 449-464.

[15] Wang, G., Wang, Y., Zhao, T., 2008. Analysis of interactions among the barriers to energy saving in China. Energy Policy, 36(6), 1879-1889.

[16] Koller, T., Williams, Z., Lovallo, D., 2012. Overcoming a bias against risk. McKinsey Insights and Publications, August 2012.

[17] Gómez-Villalva, E., Ramos, A., 2003. Optimal energy Management of an industrial consumer in liberalized markets. IEEE Transactions on Power Systems, 18(2), 716-723.

[18] Cano, E.L., Groissböck, M., Moguerza, J.M., Stadler, M., 2014. A strategic optimization model for energy systems planning. Energy and Buildings, 81, 416-423.

[19] Wickart, M., Madlener, R., 2007. Optimal technology choice and investment timing: a stochastic model of industrial cogeneration vs. heat-only production. Energy Economics 29(4), 934-952.

[20] Siddiqui, A.S., Marnay, C., 2008. Distributed generation investment by a microgrid under uncertainty. Energy, 33(12), 1729-1737.

[21] Birge, J.R., Louveaux, F., 1997. Introduction to Stochastic Programming. Springer-Verlag.

[22] Kettunen, J., Salo, A., Bunn, D.W. (2010). Optimization of electricity retailer's contract portfolio subject to risk preferences. IEEE Transactions on Power Systems, 25(1), 117-128.

[23] Pineda, S., Conejo, A.J., 2010. Scenario reduction for risk-averse electricity trading. IET generation, transmission \& distribution, 4(6), 694-705. 
[24] Carrión, M., Philpott, A.B., Conejo, A.J., Arroyo, J.M., 2007. A stochastic programming approach to electric energy procurement for large consumers. IEEE Transactions on Power Systems, 22(2), 744-754.

[25] Hochreiter, R., Pflug, G., Wozabal, D., 2006. Multi-stage stochastic electricity portfolio optimization in liberalized energy markets. Proceedings of the 22nd IFIP TC7 Conference (F. Ceragioli, A. Dontchev, H. Futura, K. Marti, and L. Pandolfi, Eds.), Springer, 219-226.

[26] Eichhorn, A., Römisch, W., 2006. Mean-risk optimization models for electricity portfolio management. Proceedings of the International Conference on Probabilistic Methods Applied to Power Systems, IEEE, 1-7.

[27] Alipour, M., Mohammadi-Ivatloo, B., Zare, K., 2014. Stochastic riskconstrained short-term scheduling of industrial cogeneration systems in the presence of demand response programs. Applied Energy, 136, 393-404.

[28] Maurovich-Horvat, L., De Reyck, B., Rocha, P., Siddiqui, A.S., 2015. Optimal selection of distributed energy resources under uncertainty and risk aversion. Working paper, Department of Statistical Science, University College London, U.K.

[29] Artzner, P., Delbaen, F., Eber, J.-M., Heath, D., 1999. Coherent measures of risk. Mathematical Finance, 9(3), 203-228.

[30] Rockafellar, R.T., Uryasev, S., 2002. Conditional value-at-risk for general loss distributions. Journal of Banking \& Finance, 26(7), 1443-1471.

[31] BMU, 2007. Germany Ministry for the Environment, CHP Report.

[32] Zhou, N., He, G., Romankiewicz, J., Fridley, D., Fino-Chen, C., 2015. A Review of Commercially Available Technologies for Developing Low-Carbon Eco-cities. Ernest Orlando Lawrence Berkeley National Laboratory Report LBNL-179304, Berkeley, CA, USA. http://eetd.lbl.gov/sites/all/files/lbnl179304.pdf. 
[33] Illindala, M., Siddiqui, A.S., Venkataramanan, G., Marnay, C., 2007. Localized aggregation of diverse energy sources for rural electrification using microgrids. Journal of Energy Engineering, 133(3), 121-131.

[34] Box, G.E., Jenkins, G.M., 1976. Time Series Analysis: Forecasting and Control. Holden-Day.

[35] Weron, R., 2007. Modeling and Forecasting Electricity Loads and Prices: A Statistical Approach. John Wiley \& Sons.

[36] Cowpertwait, P.S., Metcalfe, A.V., 2009. Introductory Time Series with R. Springer.

[37] Weron, R., 2014. Electricity price forecasting: A review of the state-of-theart with a look into the future. International Journal of Forecasting, 30(4), 1030-1081.

[38] Heydari, S., Siddiqui, A.S., 2010. Valuing a gas-fired power plant: A comparison of ordinary linear models, regime-switching approaches, and models with stochastic volatility. Energy Economics, 32(3), 709-725.

[39] Klaassen, P., 2002. Comment on 'Generating scenario trees for multistage decision problems.' Management Science, 48(11), 1512-1516.

[40] Zhao, H.X., Magoulès, F., 2012. A review on the prediction of building energy consumption. Renewable and Sustainable Energy Reviews, 16(6), $3586-3592$.

[41] Kalam, A., King, A., Moret, E., Weerasinghe, U., 2012. Combined heat and power systems: economic and policy barriers to growth. Chemistry Central Journal, 6(S1), S3.

[42] Conejo, A.J., Carrión, M., Morales, J.M., 2012. Decision Making under Uncertainty in Electricity Markets. Springer. 